\title{
Assessment of Post Obturation Radiographs for Canal Configuration in Maxillary Second Premolars - A Retrospective Study
}

Research Article

Krisha Doshi ${ }^{1}$, Pradeep Solete ${ }^{2 *}$, S.Delphine Priscilla Antony ${ }^{3}$

${ }^{1}$ Department of Conservative Dentistry and Endodontics, Saveetha Dental College, Saveetha Institute of Medical and Technical Sciences, Saveetha University, Chennai, India.

${ }^{2}$ Reader, Department of Conservative Dentistry and Endodontics, Saveetha Dental College, Saveetha Institute of Medical and Technical Sciences, Saveetha University, Chennai, India.

${ }^{3}$ Senior Lecturer, Department of Conservative Dentistry and Endodontics, Saveetha Dental College, Saveetha Institute of Medical and Technical Sciences, Saveetha University, Chennai, India.

\section{Abstract}

\begin{abstract}
Aim: The aim of this study was to assess the root canal configuration of maxillary second premolars using post obturation radiographs.

Materials and Methods: Details of endodontic procedures done in maxillary second premolar teeth June 2019 to March 2020 which constituted 746 procedures were collected retrospectively. Post obturation radiographs of these teeth were assessed for canal configuration based on Vertucci's classification. Association between gender and tooth number with Vertucci's Classification on root canal configuration was analyzed using Chi-square test.

Results: The most common variation was Vertucci's Type II (29.49\%), followed by Type I (29.09\%), Type IV (28.95\%), Type V (8.04\%), Type III $(2.41 \%)$ and Type VI (2.01\%). There was no significant difference seen between gender and prevalence of variation in maxillary second premolars based on Vertucci's classification of root canal configuration $(p>0.05)$, although males showed a slightly higher predilection for Type II configuration while females for Type I configuration. A significant difference was observed in the relation between tooth number and prevalence of variation in maxillary second premolars based on Vertucci's classification of root canal configuration $(\mathrm{p}<0.05)$.

Conclusion: Maxillary second premolars most commonly showed Vertucci's Type I, II, and IV configurations. Type V and Type VI had the least occurrence. Type VII and Type VIII configurations were not observed. Males showed a slightly higher predilection for Type II configuration while females for Type I configuration.
\end{abstract}

Keywords: Canal Configuration; Maxillary Second Premolars; Post Obturation Radiographs; Root Canal Configuration; Root Canal Morphology; Vertucci's Classification.

\section{Introduction}

The main objective of endodontic therapy is the complete debridement of necrotic and infectious tissue and disinfection of the root canal system [1], followed by a three-dimensional seal to prevent the re-entry of microorganisms. Contemporary endodontics must adhere to the following principles: a) use of aseptic technique; b) cleaning the canal thoroughly mechanically and chemically; c) shaping the canals for ease of obturation; d) proper obturation to attain a tight seal of the root canals; e) proper restoration of the tooth to prevent coronal leakage of microorganisms
[2]. Sometimes, the use of intracanal medicaments is also necessary during endodontic therapy [3]. They are anti-inflammatory and antimicrobial agents that help reduce inflammation and infection. It is vital to know the various intracanal medicaments available in the market today which will help the clinician in decision making while performing various endodontic treatments. A survey was done recently by our team, to analyze the knowledge and attitude of dental practitioners regarding the use of intracanal medicaments [4]. Among all these procedures, cleaning and shaping are considered the most important step that determines the success of the treatment [5]. Debridement of the root canal is done by the removal of organic tissues and enlargement of the

\section{*Corresponding Author:}

Pradeep Solete,

Reader, Department of Conservative Dentistry and Endodontics, Saveetha Dental College, Saveetha Institute of Medical and Technical Sciences, Saveetha University, Chennai, India. Tel: +919710404482

E-mail: pradeeps@saveetha.com

Received: November 05, 2020

Accepted: November 18, 2020

Published: November 20, 2020

Citation: Krisha Doshi, Pradeep Solete, S. Assessment of Post Obturation Radiographs for Canal Configuration in Maxillary Second Premolars - A Retrospective Study. Int J Dentistry Oral Sci. 2020;S10:02:002:7-12. doi: http://dx.doi.org/10.19070/2377-8075-SI02-010002

Copyright: Pradeep Solete ${ }^{\circ} 2020$. This is an open-access article distributed under the terms of the Creative Commons Attribution License, which permits unrestricted use, distribution and reproduction in any medium, provided the original author and source are credited. 
canal to create a suitable shape that facilitates proper cleaning, irrigation, and canal obturation [6]. Adequate cleaning and shaping of the root canal system are obtained by the use of intracanal instruments that mechanically debride the tissues as well as intracanal irrigants that chemically disinfect them. The major advantage of irrigants is their ability to flow in the nooks and crevices of the root canal system where instruments are unable to reach in order to disinfect these areas [7]. The clinician must have adequate knowledge with respect to the working, mechanism of action, toxicity, etc of these instruments and materials before attempting to use them [8]. A previous study has reported the formation of a carcinogenic precipitate on the interaction of chlorhexidine with sodium hypochlorite, neem, and tulsi [9]. With the advent of the newer NiTi rotary instruments in the market, mechanical debridements as well as adequate shaping of the canals is possible which has drastically improved the efficiency of the procedure $[10,11]$. Additionally, the development of newer formulations for intracanal irrigants has also added to the success of the endodontic treatment. Contemporary endodontics urges clinicians to practice endodontic therapy that shapes optimally and cleans more. Over preparation of the root canals to mechanically debride the canal walls must be avoided. Rather, the canals must be shaped optimally and more effort must be made to disinfect them using irrigants and irrigant activation techniques [12].

It is important to visualize and to have knowledge of the internal anatomical relationships before undertaking endodontic therapy. The anatomy of the root canal system is quite complex with variations from normal present many of the times [13, 14]. The presence of an untreated canal or incomplete disinfection of the root canal system may be a reason for failure [15]. It may lead to complications including postoperative pain, swelling, etc. postoperative pain has also been assessed by other authors [16]. A canal may be left untreated because the clinician fails to recognize its presence or because of calcification. Today, technology has enabled endodontists to negotiate even the most severely calcified canals [17], hence recognizing its presence has become more necessary. It is ethical to have a complete awareness of the complex root canal spaces that we are expected to access, shape, clean, and fill.

Over the years, clinicians and researchers have formulated and composed numerous classifications for determining root canal configurations [18-20]. Although many have been accepted, very few are widely used by clinicians all over the world. Since previous literature was inconclusive, Frank J. Vertucci in 1984, decided to conduct a detailed investigation of the anatomy of the root canals of extracted human permanent teeth. He conducted his study on 2,400 extracted human teeth and studied their internal root canal anatomy using hematoxylin dye. He came up with a classification of root canals of human permanent teeth. He classified root canals into eight types [18]:

Type I. A single canal extends from the pulp chamber to the apex. (1)

Type II. Two separate canals leave the pulp chamber and join short of the apex to form one canal. (2-1)

Type III. One canal leaves the pulp chamber, divides into two within the root, and then merges to exit as one canal. (1-2-1)

Type IV. Two separate and distinct canals extend from the pulp chamber to the apex. (2)

Type V. One canal leaves the pulp chamber and divides short of the apex into two separate and distinct canals with separate apical foramina. (1-2)

Type VI. Two separate canals leave the pulp chamber, merge in the body of the root, and redivide short of the apex to exit as two distinct canals. (2-1-2)

Type VII. One canal leaves the pulp chamber, divides and then rejoins within the body of the root, and finally redivides into two distinct canals short of the apex. (1-2-1-2)

Type VIII. Three separate and distinct canals extend from the pulp chamber to the apex (3).

Due to its simplicity, specificity, ease of understanding, reliability, and reproducibility; Vertucci's Classification has been one of the most popular classifications and is used even today.

The second maxillary premolar is among the most commonly endodontically treated teeth. Its frequency is found to be $10.3 \%$ [21]. They are also among the most difficult teeth to be treated endodontically. This could be due to the variations present in the number of roots, the number of canals, direction and longitudinal depressions of the roots, variations in pulp cavity configurations, and difficulty in visualizing the apical limit by radiograph [22]. Usually, the number of canals in maxillary second premolars is one $[23,24]$. However, there is enough evidence in the literature about the presence of a second $[25,26]$ and the third canal [25]. Moreover, non-carious cervical lesions, especially cervical abrasions are common in maxillary premolars [27] and often lead to the involvement of pulp. This increases the need for endodontic therapy in these teeth. Numerous molecular studies [28], clinical trials [29, 30], studies on material science [31, 32], in vitro studies [33, 34], surveys [35], etc. have been conducted by our team, previously, hence we decided to focus on retrospective studies. Most previous studies in this subject have used dyes to assess the root canal morphology. Since this study retrospectively assesses the prevalence of various root canal morphologies, the post obturation radiographs were used instead.

The knowledge and understanding of the variations in the root canal configuration of maxillary second premolars will make the clinician more alert while looking for these variations during the endodontic therapy. Hence the aim of this study is to assess the post obturation radiographs for canal configuration in maxillary second premolar teeth. Additionally, the association between gender and quadrant with the canal configuration according to Vertucci's classification was also assessed.

\section{Materials and Methods}

The study was conducted in an institutional online setting one researcher, one guide, and one mentor was involved in this study. Approval was obtained from the institutional review board, with ethical approval number SDC/SIHEC/2020/DIASDATA/0619-0320. Data was collected retrospectively. Patient records of 86000 patients that reported to the institution from June 2019 to March 2020 were reviewed. Out of which 746 patients 
underwent root canal treatment in maxillary second premolars. The post obturation radiographs were assessed and classification of root canal configuration was done for each tooth according to Vertucci's classification.

Excel sheet tabulations were constructed comprising age, gender, tooth number (quadrant), and Verucci's classification for the data. Teeth with improper post obturation radiographs were excluded from the study. Data was imported to SPSS software (Version 23.0). Descriptive statistics were applied to analyze the frequency and distribution of the variations in canal configuration. ChiSquare Test was used to analyze the association between gender, quadrant, and canal configuration according to Vertucci's classification.

\section{Results and Discussion}

A total of 746 premolars were included in the study. The distribution of the patients among different age groups were as follows; $18-30$ years $(23.5 \%)$; $31-40$ years $(24.1 \%)$; 41 - 50 years $(30.2 \%)$ and $>50$ years group $(22.3 \%)$ [Table 1]. The gender of the patients was males (51.2\%), and females (48.8\%). 55.5\% of the teeth were of the maxillary right second premolars while $44.5 \%$ were maxillary left second premolars.

Analysis of canal configuration showed six types of configurations according to Vertucci's classification. The distribution was as follows; Vertucci's Type I (29.09\%), Type II (29.49\%), Type III (2.41\%), Type IV (28.95\%), Type V (8.04\%) and Type VI (2.01\%). Type VII and Type VIII were not seen [Figure 1]. The post obturation radiographs of the various canal configurations are depicted in Figure 2.

The association between gender and root canal configuration based on Vertucci classification was analyzed. A higher incidence of Type II configuration was found amongst male patients and Type I configuration amongst female patients [Table 2, Figure 3]. However, this association showed no significant difference $(\mathrm{p}>0.05)$

A significant association was observed between the quadrant (tooth number) and the presence of canal configuration according to Vertucci's classification $(\mathrm{p}<0.05)$. A higher predilection of maxillary right second premolar to Type I, II, and IV configurations was observed [Table 3, Figure 4].

Success of endodontic treatment requires a correct diagnosis and careful clinical and radiographic inspection. Variations in morphology of the pulpal and root canal anatomy must always be considered before starting treatment. Knowledge of these variations and their prevalence in local populations will keep the clinician alert as to what to expect. This is more important for teeth that are endodontically difficult to treat like maxillary second premolars.

There have been various methods used to study the internal anatomy of root canals. Decalcification and clearing techniques were used in the past $[18,36]$. This technique renders the surrounding hard tissues transparent through demineralization after the placement of dyes into the root canal system. The 'Sectioning' technique involves the longitudinal and cross-sectioning of the teeth with ultra-thin diamond microtomes, burs, etc $[37,38]$. However, this technique is not widely used since it may alter the normal anatomy of minute curvatures. Radiopaque contrast media has also been used in conjunction with digital radiography to study the root canal configuration [39]. Since all the previous techniques are used only preoperatively and are applicable to extracted teeth, but, in our study, we made the use of post obturation radiographs

Table 1. This is table 1, representing the frequency and distribution of the age of patients with endodontically treated maxillary second premolars. A maximum number of endodontic procedures were done in the age group of 41-50 years.

\begin{tabular}{|c|c|c|}
\hline Age Groups & Frequency & Percent \\
\hline $18-30$ yrs & 175 & 23.5 \\
\hline $31-40$ yrs & 180 & 24.1 \\
\hline $41-50$ yrs & 225 & 30.2 \\
\hline >50yrs & 166 & 22.3 \\
\hline Total & 746 & 100 \\
\hline
\end{tabular}

Figure 1. This is figure 1 representing the frequency and distribution of canal configurations according to Vertucci's classification, observed in maxillary second premolar teeth. Maximum teeth showed Type I (Blue) - 217 (29.09\%); Type II (Green)- 220 (29.49\%); and Type IV (Purple) - 216 (28.95\%).

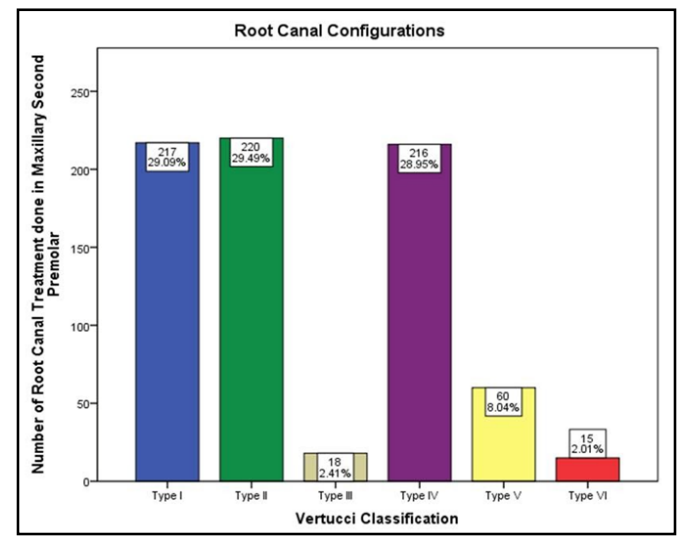


Figure 2. This is figure 2 representing the various root canal configurations of maxillary second premolar teeth as observed in the post obturation radiographs.

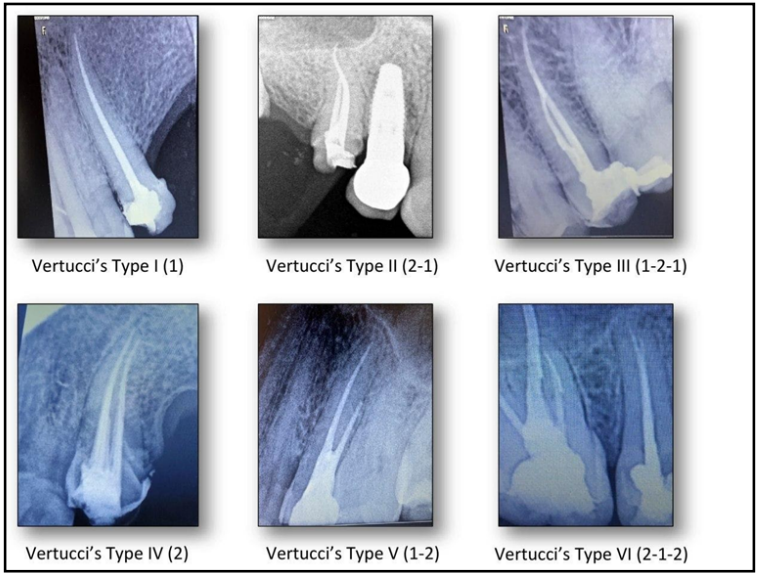

Table 2. This is table 2, representing the association between gender and prevalence of variation according to Vertucci's classification. A slight predilection of Type 2 configuration among males and Type I configuration among females was seen. Association between gender and Vertucci classification showed no significant difference. Pearson Chi-square p-val$\mathrm{ue}=.765(\mathrm{p}>0.05)$.

\begin{tabular}{|c|c|c|c|c|c|c|c|c|c|}
\hline \multirow{2}{*}{ Gender } & \multicolumn{6}{|c|}{ Vertucci Classification } & \multirow{2}{*}{ Total } & \multirow{2}{*}{$\begin{array}{c}\text { Chi Square } \\
\text { Value }\end{array}$} & \multirow{2}{*}{ P-Value } \\
\hline & Type I & Type II & Type III & Type IV & Type V & Type VI & & & \\
\hline Male & 108 & 116 & 10 & 113 & 30 & 5 & 382 & \multirow{3}{*}{2.578} & \multirow{3}{*}{0.765} \\
\hline Female & 109 & 104 & 8 & 103 & 30 & 10 & 364 & & \\
\hline Total & 217 & 220 & 18 & 216 & 60 & 15 & 746 & & \\
\hline
\end{tabular}

Figure 3. This is figure 3 representing the association between gender and prevalence of variations according to Vertucci's classification. The $\mathrm{X}$-axis represents gender; Y-axis represents the number of root canal treatments done. Vertucci's Type I (blue), Type II (green), Type IV (purple) configurations were more seen in male patients compared to female patients. Among male patients, Vertucci's Type II configuration (15.55\%) was most prevalent while among female patients, Vertucci's

Type I configuration (14.61\%) was most prevalent. However, Chi-square test showed no statistical significant difference [Chi square $\mathrm{p}$ value $=0.765,(\mathrm{p}>0.05)]$.

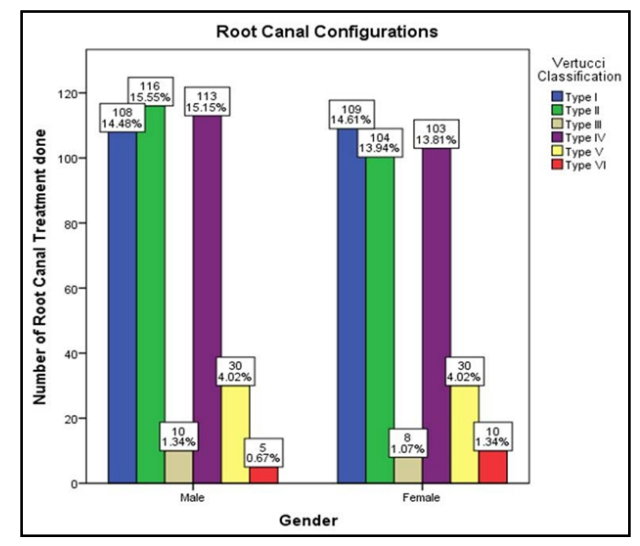

Table 3. This is table 3, representing the association between tooth number and prevalence of variations according to Vertucci's classification. A higher predilection of maxillary right second premolar to Type I, II, and IV configurations was observed. Results showed statistical significant difference, Pearson chi-square p-value $=.000(p<0.05)$.

\begin{tabular}{|c|c|c|c|c|c|c|c|c|c|}
\hline \multirow{2}{*}{ Teeth Number } & \multicolumn{6}{|c|}{ Vertucci Classification } & \multirow{2}{*}{ Total } & \multirow{2}{*}{$\begin{array}{c}\text { Chi Square } \\
\text { Value }\end{array}$} & \multirow{2}{*}{ P-Value } \\
\hline & Type I & Type II & Type III & Type IV & Type V & Type VI & & & \\
\hline $\begin{array}{c}\text { Maxillary Right Second } \\
\text { Premolar (15) }\end{array}$ & 100 & 126 & 5 & 133 & 35 & 15 & 414 & \multirow{3}{*}{29.121} & \multirow{3}{*}{0.000} \\
\hline $\begin{array}{l}\text { Maxillary Left Second } \\
\text { Premolar (25) }\end{array}$ & 117 & 94 & 13 & 83 & 25 & 0 & 332 & & \\
\hline Total & 217 & 220 & 18 & 216 & 60 & 15 & 746 & & \\
\hline
\end{tabular}


Figure 4. This is figure 4 representing the association between tooth number and prevalence of variations according to Vertucci's classification. Tooth number represented on the X-axis; the number of teeth per configuration represented on the Y-axis. Analysis amongst teeth, in maxillary right second premolar occurrence of Type IV configuration- 17.83\% (purple), in maxillary left second premolar occurrence of Type I configuration-15.66\% (Blue) were prevalent. Chi-square test showed that the association was statistically significant $[$ Chi square $p$ value $=0.000,(p<0.05)]$.

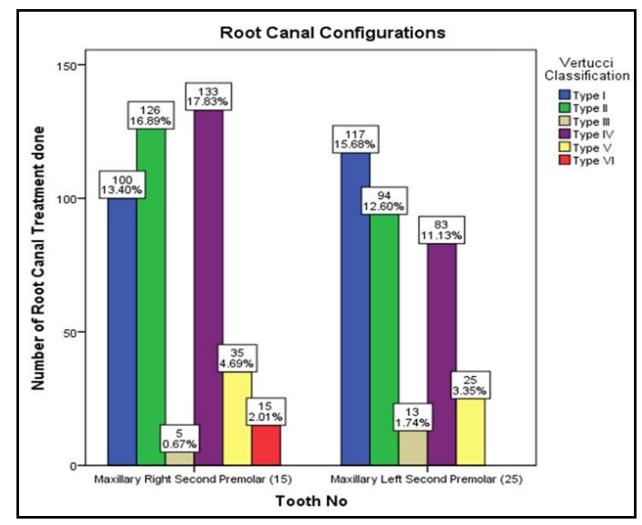

to analyze the root canal anatomy as it gives a clear picture about the root canal configurations.

In this study, the frequency and distribution of age, and gender were fairly even. This reduces bias and increases the credibility of the results. Out of 746 teeth that were included in the study, 217 (29.09\%) were of Vertucci's Type I configuration; 220 (29.49\%) were of type II; 18 (2.41\%) were type III; 216(28.95\%) were type IV; $60(8.04 \%)$ were type V and $15(2.01 \%)$ were type VI. Type VII and Type VIII configurations were not found in any teeth. This shows that $61 \%$ of the teeth ended in a single foramen while $39 . \%$ ended in two apical foramina. This is in accordance with a study by Udayakumar et al that showed $64.1 \%$ teeth had one root canal at the apex while $35.4 \%$ teeth had two root canals at the apex. Although in his study, the most common configuration found was type II $(33.6 \%)$ followed by type IV (31.1\%), type 1 (29.2\%), type V (2.1\%), type III (1.3) and type VI (1.2\%). Type VII was also observed at a frequency of $1 \%$. They also found an additional configuration, Sert and Bayirli type XIX configuration (2-1-2-1) [40]. Another study by Saad Al-Nazhan et al in 2012 showed contradictory results where more than $50 \%$ of the second maxillary premolars had two foramina [41]. Another study by Vertucci et al exhibited similar results to our study. They showed $75 \%$ of the maxillary second premolars ended at one apex while $24 \%$ had two apical foramina. Also, type I and type II showed the highest prevalence, $48 \%$ and $22 \%$ respectively [13].

When gender was compared with the prevalence of variation, no significant difference was observed. A higher prevalence of type II configuration among males and type I configuration among females was observed. This is in correlation to a study by Sert and Bayirli that showed a higher predilection of type I in females. In their study, females showed a lower predilection for type IV configuration as compared to males which also supports our study [19].

When the inter-relation between the quadrant (tooth number) and prevalence of variation was analyzed, a significant difference was found. Maxillary right second premolar showed a higher prevalence of type I, II, and IV configurations as compared to its left counterpart. This may be due to the fact that a higher number of maxillary right second premolars were endodontically treated in the Institution. Also, our study did not show the presence of type VII and Type VIII configurations which were contradicted by Vertucci et al, Sert and Bayirli et al, etc that stated that maxillary second premolar was the only tooth that exhibited all eight configurations $[13,19]$.

The limitation of this study is that the sample size is small to generalize the results to an entire population. The classification was based on the post obturation radiographs of the root canal treated maxillary second premolars of one single institution. Hence a larger population must be included in future research with the use of advanced technology like CBCT or microscopy to analyze the canal configuration more accurately.

\section{Conclusion}

Within the limitations of this study, it can be concluded that maxillary second premolars most commonly showed Vertucci's Type I, II, and IV configurations. Type V and Type VI had the least occurrence. Type VII and Type VIII configurations were not observed. Males showed a slightly higher predilection for Type II configuration while females for Type I configuration. It is of utmost importance that the clinician should be aware of all these variations in order to obtain a favorable outcome.

\section{Clinical Significance}

Success of root canal therapy majorly depends on the proper understanding of the root canal morphology. Maxillary second premolars are one of the most common but one of the most difficult teeth to treat endodontically. This is due to the numerous variations of the root canal anatomy that exist in this tooth. Failure to identify these variations will lead to unsuccessful endodontic treatment.

\section{Acknowledgments}

With sincere gratitude, the authors of this study would like to acknowledge the staff members of the Department of Conservative Dentistry and Endodontics, Saveetha Dental College for their support towards the completion of this research. 


\section{References}

[1]. Gutmann JL. Clinical, radiographic, and histologic perspectives on success and failure in endodontics. Dent Clin North Am. 1992 Apr;36(2):379-92. Pubmed PMID: 1572505.

[2]. Grossman LI . Rationale of endodontic treatment. Dent Clin North Am.1967: 483-490.

[3]. Chong BS, Ford TP. The role of intracanal medication in root canal treatment. Int Endod J. 1992 Mar;25(2):97-106.

[4]. Manohar MP, Sharma S. A survey of the knowledge, attitude, and awareness about the principal choice of intracanal medicaments among the general dental practitioners and nonendodontic specialists. Indian J Dent Res. 2018 Nov-Dec;29(6):716-720.Pubmed PMID: 30588997.

[5]. Schilder H . Cleaning and shaping the root canal. Dent Clin North Am.1974 18: 269-296.

[6]. Cohen S, Burns RC .Pathways of pulp, The CV. Mosby Co. 1984;701-749.

[7]. Zehnder M. Root canal irrigants. J Endod. 2006 May 1;32(5):389-98.

[8]. Noor SSSE, S Syed Shihaab, Pradeep. Chlorhexidine: Its properties and effects. Res J Pharm Technol.2016.; 9: 1755.

[9]. Siddique R, Sureshbabu NM, Somasundaram J, Jacob B, Selvam D. Qualitative and quantitative analysis of precipitate formation following interaction of chlorhexidine with sodium hypochlorite, neem, and tulsi. J Conserv Dent. 2019 Jan-Feb;22(1):40-47.Pubmed PMID: 30820081.

[10]. Hülsmann M, Bluhm V. Efficacy, cleaning ability and safety of different rotary NiTi instruments in root canal retreatment. Int Endod J. 2004 Jul;37(7):468-76.Pubmed PMID: 15189436.

[11]. Ramanathan S, Solete P. Cone-beam Computed Tomography Evaluation of Root Canal Preparation using Various Rotary Instruments: An in vitro Study. J Contemp Dent Pract. 2015 Nov 1;16(11):869-72.

[12]. Teja KV, Ramesh S. Shape optimal and clean more. Saudi Endodontic Journal. 2019 Sep 1;9(3):235.

[13]. Vertucci FJ. Root canal morphology and its relationship to endodontic procedures. Endod Topics. 2005 Mar;10(1):3-29.

[14]. Cohen S, Burns RC. Pathways of the pulp 8th ed. St Louis Mosby. 2002;2.

[15]. Tabassum S, Khan FR. Failure of endodontic treatment: The usual suspects. Eur J Dent. 2016 Jan-Mar;10(1):144-147.Pubmed PMID: 27011754.

[16]. Ramamoorthi S, Nivedhitha MS, Divyanand MJ. Comparative evaluation of postoperative pain after using endodontic needle and EndoActivator during root canal irrigation: A randomised controlled trial. Aust Endod J. 2015 Aug;41(2):78-87.Pubmed PMID: 25195661.

[17]. Kumar D, Antony S. Calcified Canal and Negotiation-A Review. Research J. Pharm. and Tech. 2018;11(8):3727-30.

[18]. Vertucci FJ. Root canal anatomy of the human permanent teeth. Oral Surg Oral Med Oral Pathol. 1984 Nov 1;58(5):589-99.

[19]. Sert S, Bayirli GS. Evaluation of the root canal configurations of the mandibular and maxillary permanent teeth by gender in the Turkish population. J Endod. 2004 Jun;30(6):391-8.Pubmed PMID: 15167464.

[20]. Bansal R, Hegde S, Astekar MS. Classification of Root Canal Configurations: A Review and a New Proposal of Nomenclature System for Root Canal Configuration. J Clin Diagn Res. 2018 May 1;12(5).

[21]. Hull TE, Robertson PB, Steiner JC, del Aguila MA. Patterns of endodontic care for a Washington state population. J Endod. 2003 Sep;29(9):553-6. Pubmed PMID: 14503824 .

[22]. Awawdeh L, Abdullah H, Al-Qudah A. Root form and canal morphology of Jordanian maxillary first premolars. J Endod. 2008 Aug;34(8):956-61. Pubmed PMID: 18634927.

[23]. Sussman HI. Caveat preparator: maxillary second bicuspid root invagina- tions. N Y State Dent J. 1992 Oct;58(8):36-7.Pubmed PMID: 1407859.

[24]. San Chong B. Harty's Endodontics in Clinical Practice E-Book. Elsevier Health Sciences; 2016 Jul 28

[25]. Kartal N, Özçelik B, Cimilli H. Root canal morphology of maxillary premolars. J Endod. 1998 Jun 1;24(6):417-9.

[26]. Soares JA, Leonardo RT. Root canal treatment of three-rooted maxillary first and second premolars--a case report. Int Endod J. 2003 Oct;36(10):705-10. Pubmed PMID: 14596244.

[27]. Wood I, Jawad Z, Paisley C, Brunton P. Non-carious cervical tooth surface loss: a literature review. J Dent. 2008 Oct;36(10):759-66.Pubmed PMID: 18656296.

[28]. Teja KV, Ramesh S, Priya V. Regulation of matrix metalloproteinase-3 gene expression in inflammation: A molecular study. J Conserv Dent. 2018 Nov;21(6):592-596.

[29]. Janani K, Palanivelu A, Sandhya R. Diagnostic accuracy of dental pulse oximeter with customized sensor holder, thermal test and electric pulp test for the evaluation of pulp vitality: an in vivo study. Braz. Dent. Sci. 2020 Jan 31;23(1):8.

[30]. Hussainy SN, Nasim I, Thomas T, Ranjan M. Clinical performance of resinmodified glass ionomer cement, flowable composite, and polyacid-modified resin composite in noncarious cervical lesions: One-year follow-up. J Conserv Dent. 2018 Sep-Oct;21(5):510-515.Pubmed PMID: 30294112.

[31]. Ravinthar K. Recent advancements in laminates and veneers in dentistry. Res J Pharm Technol. 2018;11(2):785-7.

[32]. Rajakeerthi R, Ms N. Natural Product as the Storage medium for an avulsed tooth-A Systematic Review. Cumhur. Dent. J. 2019;22(2):249-56.

[33]. Rajendran R, Kunjusankaran RN, Sandhya R, Anilkumar A, Santhosh R, Patil SR. Comparative Evaluation of Remineralizing Potential of a Paste Containing Bioactive Glass and a Topical Cream Containing Casein Phosphopeptide-Amorphous Calcium Phosphate: An in Vitro Study. Pesqui. Bras. Odontopediatria Clin. 2019;19

[34]. Nandakumar M, Nasim I. Comparative evaluation of grape seed and cranberry extracts in preventing enamel erosion: An optical emission spectrometric analysis. J Conserv Dent. 2018 Sep-Oct;21(5):516-520.Pubmed PMID: 30294113.

[35]. Jose J, Subbaiyan H. Different Treatment Modalities followed by Dental Practitioners for Ellis Class 2 Fracture-A Questionnaire-based Survey. Open Dent. J. 2020 Feb 18;14(1).

[36]. Seelig A, Gillis R. Preparation of cleared specimens for pulp cavity studies. J Dent Res. 1973 Sep;52(5):1154.

[37]. Green D. Double canals in single roots. Oral Surg Oral Med Oral Pathol. 1973 May 1;35(5):689-96

[38]. Weine FS, Healey HJ, Gerstein H, Evanson L. Canal configuration in the mesiobuccal root of the maxillary first molar and its endodontic significance. Oral Surg Oral Med Oral Pathol. 1969 Sep 1;28(3):419-25.

[39]. Neelakantan P, Subbarao C, Subbarao CV. Comparative evaluation of modified canal staining and clearing technique, cone-beam computed tomography, peripheral quantitative computed tomography, spiral computed tomography, and plain and contrast medium-enhanced digital radiography in studying root canal morphology. J Endod. 2010 Sep;36(9):1547-51.Pubmed PMID: 20728725

[40]. Jayasimha Raj U, Mylswamy S. Root canal morphology of maxillary second premolars in an Indian population. J Conserv Dent. 2010 Jul;13(3):148-51. Pubmed PMID: 21116391.

[41]. Al-Nazhan S, Al-Daafas A, Al-Maflehi N. Radiographic investigation of in vivo endodontically treated maxillary premolars in a Saudi Arabian sub-population. Saud Endod J. 2012 Jan 1;2(1):1. 